Rosangela Gaze

(D) https://orcid.org/0000-0002-7909-9247

Luiz Carlos Fadel de Vasconcellos

(iD) https://orcid.org/0000-0002-7679-9870

a Universidade Federal do Rio de Janeiro (UFRJ), Centro de Ciências da Saúde, Instituto de Estudos de Saúde Coletiva. Rio de Janeiro, RJ, Brasil.

${ }^{\text {b } F u n d a c ̧ a ̃ o ~ O s w a l d o ~ C r u z ~(F i o c r u z), ~}$ Escola Nacional de Saúde Pública, Departamento de Direitos Humanos, Saúde e Diversidade Cultural. Rio de Janeiro, RJ, Brasil.

Contato:

Rosangela Gaze

E-mail:

rosangelagaze@iesc.ufrj.br

Os autores informam que o trabalho não foi baseado em dissertação ou tese e que não foi apresentado em evento científico.

Os autores declaram que o trabalho não foi subvencionado e que não há conflitos de interesses.

\section{Exposicao ocupacional à hepatite C: saber operário e rotas inexploradas de propagação do vírus}

\author{
Occupational exposure to hepatitis C: worker knowledge and \\ unexplored routes of virus spread
}

\section{Resumo}

Introdução: lacuna de 50\% na identificação de fontes de transmissão do vírus da hepatite C (HCV) torna plausível suspeitar da existência de elos epidemiológicos desconsiderados entre a infecção e acidentes de trabalho. Objetivo: apresentar e fundamentar hipótese de existência de rotas inexploradas de transmissão ocupacional do HCV por exposição a sangue/fluidos humanos em processos e ambientes de trabalho de qualquer setor produtivo. Métodos: análise baseada em revisão bibliográfica e documental em busca de evidências que possam relacionar a infecção pelo HCV a acidentes de trabalho e acerca da importância da articulação entre conhecimento acadêmico e saber dos trabalhadores na sua identificação e controle. Discussão: dados de acidentes com exposição a agente biológico destacam ocupações não comumente consideradas em estudos do HCV. Magnitude, infecção silenciosa e de longo curso e viabilidade ambiental do HCV por 16-23 horas conferem plausibilidade à hipótese de sua propagação em acidentes com ruptura de barreira cutânea, pelo contato direto entre trabalhadores e, indireto, no compartilhamento de instrumentos/ferramentas/robôs. Análises epidemiológicas que considerem o processo de trabalho podem contribuir para melhor compreensão da transmissão ocupacional do HCV. Os trabalhadores também devem protagonizar posição estratégica no desenvolvimento de investigações, indicadores e intervenções em todos os setores produtivos.

Palavras-chave: vigilância em saúde do trabalhador; hepatite C; acidentes de trabalho; exposição ocupacional; saúde do trabalhador.

\begin{abstract}
Introduction: a 50\% gap in identifying sources of the hepatitis $C$ virus (HCV) transmission suggests the existence of disregarded epidemiological associations between this infection and work accidents. Objective: to present and support the hypothesis of unexploited routes of HCV occupational transmission in any productive sectors due to their own work processes and environments. Methods: bibliographic and documentary review searching evidence of the association between HCV infection and work accidents as well as verifying the importance of the articulation between academic knowledge and worker's knowledge regarding the disease identification and control. Discussion: data from accidents involving exposure to biological agents highlight occupations not typically considered in HCV studies. Magnitude, silent and long-term infections as well as environmental susceptibility to HCV for 16-23 hours make the hypothesis of propagation in accidents with skin rupture plausible when there is direct contact between workers and indirectly through the sharing of instruments/tools/ robots. Epidemiological analyses considering the work process may contribute to a better understanding of HCV occupational transmission. Workers must also play a strategic role in research activities, indicators definition and intervention actions in all productive sectors.
\end{abstract}

Keywords: workers' health surveillance; hepatitis C; work accidents; occupational exposure; occupational health. 


\section{Introdução}

Este ensaio visa iluminar rotas inexploradas de transmissão do vírus da hepatite C (HCV) pela exposição ocupacional a sangue/fluidos humanos por meio de análise baseada em revisão bibliográfica e documental em busca de evidências que possam relacionar a infecção pelo HCV a acidentes de trabalho e acerca da importância da articulação entre conhecimento acadêmico e saber dos trabalhadores na sua identificação e controle. A motivação para as reflexões apresentadas deve-se a insights dos autores, em diálogos com trabalhadores, durante práticas pedagógicas de cursos de formação em Vigilância em Saúde do Trabalhador (Visat) ${ }^{1}$.

Embora o trabalho enfrente desafios para se sustentar como categoria central da vida ${ }^{2}$, o mundo do trabalho permeia seu caminhar e, ainda que a reestruturação produtiva se empenhe em esfumaçar seu valor (ou o da classe trabalhadora), sua historiografia gravou seus passos. Compreender intencionalidades de modelos econômicos no esvaziamento da relevância do trabalho é, de certo modo, mais simples do que explicar lacunas epidemiológicas na identificação de processos condicionantes de agravos em que o trabalho não é considerado variável analítica de dados. Essas ausências estariam sob a influência da acumulação flexível em que prevalece o capital sobre a saúde dos trabalhadores? Ou refletem apenas a "acomodação" da produção científica baseada na reprodutibilidade de evidências?

A ocupação é considerada variável epidemiológica apenas nos acidentes e "clássicas" doenças relacionadas ao trabalho. Mesmo quando "novos" riscos são identificados, o referencial investigativo fundamenta-se em conceitos estabelecidos a priori. Considerando as três rotas mais frequentemente implicadas na infecção aguda por HCV - abuso de drogas, nosocomial e entre homens que praticam sexo com homens, segundo relatórios epidemiológicos $^{3}$-, torna-se difícil compreender a magnitude global da infecção por HCV.

Estima-se que cerca de 2,5\% da população mundial (177,5 milhões de pessoas) esteja infectada pelo HCV, que apresenta importante diversidade genotípica (genótipos G1 a G7, sendo os G1 a G6 os mais frequentes) ${ }^{4}$, com novos genótipos sendo identificados. Cirroses e hepatocarcinomas pelo HCV lideram as causas de transplantes ${ }^{5}$ e ocasionam cerca de 399 mil óbitos por ano ${ }^{6}$. De 100 infectados, 15-25 desenvolvem imunidade espontânea, 75-85 cronificam e, se não tratados, 5-20 evoluem para a cirrose em 20-30 anos e 1-5 podem desenvolver hepatocarcinoma $^{5}$. Imunizantes não estão disponíveis, mas antivirais podem "clarear" o vírus em cerca de 90\% das infecções ${ }^{5}$ - dependendo do genótipo e subti$\operatorname{pos}^{4}$, gravidade, comorbidades -, reduzindo o risco de transmissão e agravamento da doença.

A Assembleia Mundial da Saúde de 2016 (AMS 2016) endossou a Estratégia do Setor de Saúde Global de eliminação das hepatites virais como ameaça à saúde pública em 2030 (redução de 90\% na incidência e de 65\% na mortalidade), sendo necessário, no mínimo, o diagnóstico de $90 \%$ dos infectados e tratamento de $80 \%$ destes. O esquema terapêutico recomendado para adultos baseia-se no uso de antivirais pangenotípicos de ação direta. Em síntese, a estratégia fundamenta-se na ampliação diagnóstica e terapêutica e elenca grupos populacionais que merecem abordagens específicas devido à elevada incidência/prevalência, vulnerabilidades e dificuldades de acesso a serviços (detentos, homens que praticam sexo com homens, trabalhadores do sexo, indigentes e migrantes) ${ }^{6}$.

Para que as metas da AMS 2016 sejam atingidas, é cabível a problematização e superação de lacunas de informação e, possivelmente, de conhecimento acerca das rotas de propagação do HCV, considerando os gaps de até $50 \%$ nas fontes/mecanismos de transmissão dos casos referidos na literatura. Recente estudo da carga global das hepatites virais (HV) destaca a escassez de pesquisas populacionais, dificultando avaliações de impacto do tratamento no controle da transmissão ${ }^{7}$. Tabulações e testes estatísticos têm seu papel, mas pouco resultado pode ser extraído pela sua aplicação a dados exaustivamente pesquisados. Novos questionamentos são requeridos quando as respostas permanecem a meio caminho.

A distribuição dos casos de hepatite $C$ sugere tratar-se de infecção predominante em homens nas faixas etárias produtivas ${ }^{5}$, perfil também encontrado nos acidentes típicos de trabalho ${ }^{8}$, sendo plausível suspeitar da existência de elo epidemiológico inexplorado entre a transmissão do HCV e os acidentes típicos de trabalho em diversos setores produtivos. Acidentes de trabalho com ruptura de barreira cutânea ocorrem diariamente em diversos processos e ambientes laborais ${ }^{9}$.

O silêncio epidemiológico, político e social é outra coincidência que entrelaça a infecção pelo HCV aos acidentes de trabalho de qualquer gravidade, em especial os pequenos acidentes com ruptura de barreira cutânea, que, subvalorizados e (decerto) não notificados, abrem porta de entrada à inaparente infecção pelo HCV.

No contexto da acumulação flexível, a ótica do empregador é atingir espaço zero nos processos de produção e a automatização de processos é uma das estratégias de ganho de capital. A utilização de robôs compartilhados entre trabalhadores é uma realidade em todas as cadeias produtivas. Homem e máquina 
exercendo atividades em equipe pode parecer a realização de objetivos a que o ser humano sempre se empenhou. Afinal, um dos atributos humanos é a produção de facilitadores - os meios de trabalho - da execução do trabalho ${ }^{10}$. "Facilitadores" e não vítimas de sua criatura numa reedição perversa dos tempos luditas, em que os trabalhadores não apenas são obrigados a cederem seu emprego aos robôs; mas, por estes, são irônica e "cirurgicamente" infectados sem que esta possibilidade seja cientificamente suspeitada.

Neste ensaio, apresenta-se e fundamenta-se a hipótese de existência de rotas inexploradas de transmissão ocupacional do HCV por exposição a sangue/fluidos humanos em processos e ambientes de trabalho de diversos setores produtivos, visto que sangue e fluidos humanos podem atingir trabalhadores direta ou indiretamente envolvidos ${ }^{11}$.

\section{Fundamentação da hipótese: rotas inexploradas de transmissão ocupacional - reconhecendo lacunas de informação para preservar barreiras cutâneas}

Em recente publicação ${ }^{6}$, a Organização Mundial da Saúde elenca como rotas de transmissão do HCV: transmissão associada a cuidados de saúde, transmissão entre usuários de drogas injetáveis e outras (vertical, aplicação de tatuagem e pingentes, acidentes com agulhas hipodérmicas usadas e entre homens que fazem sexo com homens, sendo mais frequente nos casos de coinfecção HIV-HCV). Esse guia destaca ainda a infrequente transmissão heterossexual do HCV e as "práticas inadequadas" e "uso excessivo de injeções" como potencializadores e mantenedores da "transmissão do HCV", demandando maior segurança nos cuidados de saúde.

Revisões bibliográficas não encontraram documentos que indicassem o risco de exposição ocupacional ao HCV segundo setores produtivos em geral, apesar da constante ressalva dos textos de referência $^{7,12}$, protocolos e relatórios da vigilância epidemiológica americana ${ }^{13}$ e europeia ${ }^{3}$ acerca da limitada representatividade das informações sobre as fontes/ mecanismos de transmissão baseadas em cerca de $50 \%$ dos casos; e 53,7\% no Brasil ${ }^{14}$ (p. 24).

O mais conhecido fator explicativo e limitante na obtenção de informações sobre fontes de contaminação é o curso longo (20-30 anos) e silencioso da infecção pelo HCV, visto que $70 \%$ a $80 \%$ das infecções recentes e a maior parte dos casos crônicos são usualmente assintomáticos ou apresentam sintomas leves e inespecíficos (fadiga, inapetência, depressão, dor abdominal) ${ }^{5}$ tornando improvável ou retardando a procura de assistência à saúde. Na prática, essa infecção não é reconhecida até que casos assintomáticos sejam detectados em triagem na doação de sangue ou exames de rotina, quando a investigação de fontes de contaminação perde até mesmo o sentido. Condicionada à memória do paciente e à habilidade do entrevistador no resgate da história social, desvendar detalhes do percurso das pessoas na procura de exposições a sangue/fluidos humanos em amplitude de tempo que pode variar entre duas semanas a 30 ou mais anos é quase uma quimera.

\section{Proporções e imagens na construção de evidências}

Em 2017, no Brasil, estimava-se a ocorrência de 363.551 acidentes com ruptura de barreira cutânea entre trabalhadores celetistas ${ }^{15,16}$ e 200.839 infecções por HCV foram confirmadas entre $1999-2017^{14}$ (p. 7). Tomou-se o total acumulado, visto ser mais apropriado ao planejamento de ações de controle devido à magnitude e ao potencial de propagação silenciosa do HCV.

A investigação de acidentes de trabalho com ruptura de barreira cutânea, em diversos setores produtivos, não leva em consideração que um dos atributos do HCV é seu potencial de viabilidade ambiental que pode chegar a 16 ou 23 horas, conforme demonstrado em análises genômicas ${ }^{17,18}$.

A chave para a compreensão da propagação do HCV está na investigação que considera como objeto do estudo epidemiológico o "modo" como ocorreu a exposição ao sangue/fluidos corporais, independentemente do local (serviço de saúde, presídio, bordel, oficina de estética, campo esportivo etc.), gênero, origem geográfica (migrantes), renda ou ocupação. Uma infecção crônica, subclínica e de elevada prevalência pode estar presente em pessoas em qualquer ambiente, evoluindo silenciosamente por esteira de tempo mais ou menos alongada no seu curso para a cronicidade, cirrose e/ou câncer de fígado. Daí defender-se o pressuposto de que sua transmissão possa ocorrer em qualquer processo de trabalho.

Relatório técnico do European Centre for Disease Preventionand Control ${ }^{19}$ (p. 27) - ao estudar exaustivamente a epidemiologia das hepatites B e C em grupos selecionados na União Europeia/Área Econômica Europeia - oferece argumentos para reflexão, como a escassez de estimativas consistentes de prevalência do HCV na população geral, e menciona grande amplitude de variação na proporção estimada de casos não diagnosticados de HCV na população geral (Dinamarca, 20\%; Grécia, 91,2\%) e 59\% entre usuários de drogas injetáveis. Em especial, alerta para 
a heterogeneidade de métodos dessas estimativas ("opinião de especialistas", "estudos de modelagem" e "rastreamento") e para o relevante impacto desse viés de seleção na precisão de estudos epidemiológicos populacionais. Refere, ilustrando, que a oferta de testes assim planejada "provavelmente" resultará em segmentação de pessoas que desconhecem sua infecção, superestimando-se a fração não diagnosticada. Ressalta a importância da padronização de métodos para que se produzam análises epidemiológicas comparativas. Entretanto, não parece que o risco de superestimativas possa ser expressivo diante das repetidas referências ao desconhecimento de rotas de transmissão do HCV.

Ao contrário, é factível acreditar que superar as limitações dos estudos que fragmentam a população em grupos de maior risco, excluindo os múltiplos condicionantes do complexo mundo do trabalho das análises epidemiológicas, seja central ao planejamento racional e justo da oferta de ações de prevenção e controle do HCV.

Práticas preventivas da exposição ocupacional ao HCV entre desportistas - comprovadas por análise genômica $^{20}$ - foram incorporadas às normativas de competições esportivas ${ }^{21}$. Sem a cobertura midiática do futebol, cortes/lacerações/abrasões são lesões corriqueiras que exsudam fluidos corporais nos acidentes de trabalho em diversos setores produtivos. Naturalizados pela elevada frequência e geralmente baixa gravidade (exceto ao atingir segmentos corporais valorizados), são sub-registrados por empregadores e trabalhadores ${ }^{22}$.

A regulação americana de segurança e saúde no trabalho acerca de patógenos de transmissão sanguínea, embora defina que qualquer pessoa (viva ou morta) e seus materiais/fluidos podem ser fonte de contaminação, revela o foco prioritário ao ilustrar - circunscrevendo como "de risco" - os ambientes em que circulam/ aram pacientes ou seus elementos biológicos ${ }^{23}$.

Considerações acerca de riscos e sub-registros podem estar condicionadas a motivos inaudíveis e contundentes. Conforme captado nos documentários de Beto Novaes ${ }^{24}$, a "pureza” da fala de crianças aviltadas pelo trabalho no campo constata a evidência de que muitas entram em contato com sangue/ fluidos humanos, mas o silêncio lhes é imposto pelo patronato e pelo isolamento social inerente às condições de sobrevivência. Relatos e imagens expressivas da potencial circulação de matéria biológica humana (Sonhos de criança), de seu silenciamento (Trabalhadores invisíveis) e da abrangência da situação (Meninos da roça) contribuíram para a construção de evidências narrativas para a fundamentação da hipótese. Textos científicos muitas vezes limitam-se a considerar o conhecimento validado por evidências reproduzíveis cujas singularidades são excluídas. Entretanto, relatos "únicos” podem expressar reprodutibilidades que registros formais não são adequados para captar.

É bem conhecido que explorar, investigar e identificar determinantes sociais de adoecimento requer transpor referenciais teóricos das ciências (saúde, humanas, sociais, matemáticas etc.) e dialogar com aportes outros, como as artes, integrando, no mesmo patamar valorativo, múltiplos saberes para a análise e interpretação dos problemas em foco.

Agulhas - no uso de drogas e nosocomiais -, bisturis, instrumentos cirúrgicos e endoscópios podem carrear o HCV. Tesouras automáticas, desossadores, facões, torneadores mecânicos e uma infinidade de ferramentas, instrumentos e máquinas nas fábricas e no campo - cujas lesões acidentais costumam ser mais extensas e profundas - podem carrear grande volume de inóculos do HCV ao vitimarem um trabalhador, inclusive aqueles que inadvertidamente portam a infecção "inaparente” pelo HCV. Problema que se amplifica, considerando que os meios de trabalho envolvidos nesses acidentes não costumam ser esterilizados antes que o próximo trabalhador venha a manejá-los.

O Observatório Digital de Segurança e Saúde no Trabalho (Observatório Digital SST) ${ }^{15}$ divulgou que entre 2012 e 2018 foram registrados 3.100.000 acidentes de trabalho (com comunicação de acidente de trabalho - CAT) entre os trabalhadores regidos pela Consolidação das Leis do Trabalho (CLT). Em 40\% desses casos, as lesões, por sua natureza (corte, laceração, ferida contusa, punctura-18\%; contusão, esmagamento-15\%; escoriação, abrasão-6\%; e amputação ou enucleação-1\%), levaram à ruptura de barreira cutânea de diversos graus de intensidade, propiciando contato com sangue e fluidos humanos, diretamente, entre trabalhadores, e, indiretamente, através de instrumentos de trabalho (ferramentas, máquinas, equipamentos, utensílios e veículos) ${ }^{10}$. Considere-se ainda o sub-registro significativo mesmo entre os celetistas ${ }^{25,26}$.

O Observatório Digital SST ${ }^{15}$, opção “perfil dos casos-CAT”, passou a divulgar análises epidemiológicas de acidentes de trabalho para a variável ocupação, disponibilizando tabulações, dentre outras, segundo o agente causador. Verificou-se que no Brasil (2012 a 2018), a ocupação “carteiro” liderou o ranking $(6.472-30,46 \%)$ de notificações de acidentes de trabalho causadas por "agente biológico”, no total de 21.250 notificações. Destaque-se que, além das classicamente reconhecidas (da saúde e da limpeza), aparecem acidentes com exposição a material biológico nas ocupações: atendente comercial em agência postal (894 - 4,21\%), faxineiro (762 $3,59 \%)$, motorista de furgão e/ou veículo similar (512 - 2,41\%), servente de obras (370 - 1,74\%), 
cozinheiro geral (310 - 1,46\%), auxiliar nos serviços de alimentação $(276-1,30 \%)$, copeiro (238 $1,12 \%)$ e outras não consideradas pelos estudos de carga do $\mathrm{HCV}^{7}$ e de epidemiologia ocupacional ${ }^{9}$.

Essas análises epidemiológicas adicionaram consistência às hipóteses apresentadas e são emblemáticas do papel estratégico do saber operário enlaçado ao saber técnico-científico - alicerçado na ética e na justiça social - e na ampliação do conhecimento ${ }^{10,11}$. Os pressupostos deste ensaio partiram da valorização articulada/orgânica dos conhecimentos dos trabalhadores e de suas subjetividades pelos professores dos cursos de Visat ${ }^{1}$ que colocaram seu aporte técnico a favor da saúde dos trabalhadores ${ }^{10}$.

Como bem estabelecido pelo conhecimento acerca da dinâmica do processo saúde-doença, essas evidências epidemiológicas/estatísticas necessitam de contínuas investigações específicas, as quais podem atualizar informações sobre rotas de propagação, revelando novas exposições ou constatando o controle de antigas exposições pelas modificações (positivas e negativas) introduzidas em processos de trabalho.

Ressalvando que os dados se referem apenas a ocorrências notificadas por meio da CAT, excluindo possíveis acidentes de trabalho nos $37,01 \%$ (33,8 milhões) de pessoas ocupadas sem registro formal de trabalho no trimestre julho/agosto/setembro de 2017 (IBGE ${ }^{16}$ ). Maia et al. ${ }^{22}$, comparando bases distintas de dados Pesquisa Nacional de Saúde (PNS) e Anuário Estatístico da Previdência Social (AEPS) -, observaram que "a metade dos acidentes referidos na PNS é de população segurada", resultando em " $245 \%$ a mais de acidentes referidos do que os registrados na Previdência Social", ilustrando as frações desconhecidas do que se acredita estar registrado (p. 9).

Hennington mencionou que a Organização Internacional do Trabalho (OIT) estima que os acidentes de trabalho podem impactar em $4 \%$ o produto interno bruto (PIB) mundial e que o Brasil é o quarto país no ranking, com cerca de 700 mil acidentes, 11 mil incapacitados permanentes e 2.500 mortes anuais $^{27}$. Alerta que, mesmo alarmante, esse quantitativo se refere à fração visível de um iceberg, pois se estima uma subnotificação de $80 \%$.

Em outras palavras, como alguns parecem exultar, o desemprego no Brasil vem sendo "superado" por perdas em saúde e os ganhos em renda da população ocupada ${ }^{16}$ são perdidos nos custos pessoais e sociais do adoecimento e morte, onerando o Sistema Único de Saúde (SUS) e o "deficitário" sistema previdenciário. Reforçam a triste constatação do que Bernardino Ramazzini nos anos $1700^{28}$ (p. 95) sinalizava: "Muitas outras oficinas existem que são pestíferas para o olfato e compensam os ganhos dos seus operários impondo-lhes um tributo de males [...]".

\section{Entrelaçando saberes para caminhar no conhecimento}

Pressupondo-se que as vítimas de acidentes com ruptura de barreira cutânea podem ter sido duplamente atingidas - adquirindo inadvertidamente o HCV -, pode-se ter uma estimativa mais aproximada da realidade epidemiológica dos dois agravos tratados aqui com a necessária complexidade e gravidade que apresentam. Vasconcellos ${ }^{26}$ (p. 6) menciona que

[...] analisar o mundo do trabalho com determinado olhar técnico, de modo a observar riscos, cargas de trabalho, situações de vulnerabilidade, fenômenos que podem ocorrer e os que já ocorreram e a subjetividade dos trabalhadores em seus locais de trabalho, dá mais sentido à VISAT.

Ousa-se afirmar que é esse sentido que se persegue ao entrelaçar dados e saberes de fontes diversas na produção das análises epidemiológicas que propiciaram reflexões e a construção de novo pressuposto.

O desafio proposto continua alinhado ao "Decálogo para uma tomada de posição", de Vasconcellos ${ }^{26}$ (p. 1), ao visar verificar a consistência da hipótese e, caso comprovada ou não, continuar a desenvolver ações que possibilitem a escuta privilegiada de silêncios epidemiológicos pela troca de saberes com os trabalhadores ${ }^{11}$. Desafio que se supõe como o mais efetivo na apropriação e transformação da realidade na direção da meta zero de adoecimento e morte no trabalho. Nesse diálogo transformador do conhecimento, insere-se o Fórum Intersindical Saúde-Trabalho-Direito (Rio de Janeiro ${ }^{29}$ como espaço privilegiado de articulação entre o conhecimento acadêmico tradicional e o saber empírico dos trabalhadores que produzem conhecimento não desvelado em suas atividades cotidianas.

Cipeiros costumam ser sistematicamente capacitados e reciclados com base em currículos que reproduzem os objetivos da saúde ocupacional e limitam-se muitas vezes a transferir conteúdos sobre o uso de equipamentos de proteção individual e, no caso específico da prevenção da infecção por HCV, à "conscientização" sobre a importância do uso de preservativo e da prática do sexo seguro. Seria essa mais uma forma sutil de culpabilizar a vítima de acidente de trabalho que se descobre posteriormente (quando nem lembra mais do acidente) portadora do HCV?

A mudança de currículo de formação de cipeiros tornando obrigatória a "formação básica" em Visat poderá contribuir para reforçar o valor do conhecimento dos trabalhadores sobre seus processos 
e ambientes de trabalho ${ }^{26}$ (p. 6). A valorização do protagonismo dos trabalhadores na construção do conhecimento, entrelaçada às demais atribuições dos Centros de Referência em Saúde do Trabalhador (Cerest), tem o potencial de esclarecer as lacunas epidemiológicas e de gestão no SUS, contribuindo para a construção de indicadores de Visat transformadores da "indiferença operacional" no sistema ${ }^{30}$ (p. 614). Através da visão e da escuta privilegiada desses atores sociais - sistematicamente excluídos das vigilâncias - é possível obter dados originais.

Com o auxílio das modernas e acessíveis tecnologias de gravação e transmissão de áudio e imagens - incorporadas como técnicas de construção de indicadores e integradas ao fluxo de informações -, as vigilâncias podem ampliar e agilizar seus recursos diagnósticos no desencadeamento de ações preventivas praticamente em tempo real. Nesse caso, especialmente, haveria a participação proativa dos trabalhadores como vigilantes de ponta, em seus espaços de trabalho. Utopia? Toma-se essa reflexão como desafio criativo.

Coortes de doadores têm sido acompanhadas sob sofisticadas análises estatísticas utilizando variáveis sociodemográficas e rotas de transmissão similares às dos sistemas de vigilância epidemiológica (SVE), resultando em interpretações "similares"31,32. Karmochkine et al. ${ }^{33}$ mostraram que investigar dados ignorados, explorando outras possibilidades, clareou exposições a risco desconhecidas. Em estudo caso-controle, esses autores arrolaram 450 doadores soropositivos e detectaram fatores de risco previamente não identificados ( $20 \%$ a $40 \%$ dos doadores), como esportes de contato e manicure/pedicure profissional.

Magnitude e variabilidade genômica do HCV global sugerem sua propagação há mais tempo. Admite-se que os fluxos migratórios - multidirecionais - contribuíram para disseminação no colonialismo escravagista ${ }^{34}$, período de intensa exposição ocupacional a sangue/fluidos corporais. Na revolução industrial esta exposição esteve presente e possivelmente em escala amplificada pela mobilidade humana e aumento de postos de trabalho. A dinâmica do HCV na reestruturação produtiva em curso na pós-modernidade e a intensificação dos movimentos migratórios tornam impensáveis a exclusão da variável ocupação das análises epidemiológicas.

Gravidade, magnitude e premência no controle da hepatite $\mathrm{C}$ - e reconhecimento de lacunas de informação - são consenso internacional ${ }^{5}$. A "senha" de superação dessa grave pandemia, acredita-se, pode estar na revalorização da abordagem antropológica entrelaçada à "engenharia" (Estatística, Epidemiologia, Informática) de concepção de sistemas de monitoramento mais aptos a detectar indícios e construir indicadores oportunos à complexidade da hepatite $\mathrm{C}$ no trabalho.

Os trabalhadores - vítimas destes acidentes - ocupam também posição estratégica na identificação de pontos críticos de sua ocorrência e no desenvolvimento de indicadores, propostas e intervenções transformadoras de ambientes e processos de trabalho no sentido de evitar acidentes. O "privilégio" desses trabalhadores de conhecerem o cenário e a cena em que os acidentes acontecem os caracteriza como atores estratégicos da vigilância epidemiológica na superação da escassez de dados, apontada por estudos de carga da doença e relatórios epidemiológicos, minimizando dificuldades no cumprimento de metas de eliminação das hepatites virais como problema de saúde pública até $2030^{5}$.

A participação de trabalhadores integrantes do Fórum Intersindical Saúde-Trabalho-Direito (2015) com seu saber e inserção social - na proposição metodológica aplicável a eventuais pesquisas sobre o tema pode contribuir para a geração de conhecimento transdisciplinar inovador, ratificando o papel das ciências sociais e humanas na saúde pública ${ }^{35}$.

Pesquisas futuras de sequenciamento genômico visando detectar potencial similaridade de quasispecies entre pessoa fonte e exposta e entre meios de trabalho (por exemplo, robôs compartilhados) e trabalhador exposto poderão ser desenvolvidas. Dialogar com o significado de quasispecies na Virologia pode interessar à abordagem que os sistemas de vigilância precisariam adotar: As variantes genéticas do HCV podem ser compreendidas como uma nuvem (quasispecies) que interage cooperativamente e contribui para as características da população ${ }^{36}$.

Dessas interações com os trabalhadores resultará a construção metodológica, fundamentada nas concepções da Visat ${ }^{10}$, estabelecendo-se prioridades nas investigações de acidentes de trabalho graves, com ruptura de barreira cutânea em todos os setores produtivos.

\section{Implicações práticas da comprovação da hipótese}

A profilaxia pós-exposição (PEP) em acidentes com material biológico - restrita aos trabalhadores da saúde e de ocupações que manejam fluidos corporais e materiais que os contenham - tem possibilitado o controle da transmissão sanguínea de patógenos ${ }^{37}$.

A Lista de Doenças Ocupacionais da OIT inclui as hepatites virais como "agentes biológicos causadores de doenças infecciosas e parasitárias" e as hepatites B e C como "agentes causadores de câncer ocupacional" e considera que não apenas os trabalhadores da saúde têm risco de exposição ocupacional ao HIV, 
mas também bombeiros, agentes prisionais e "outros"38. Outros são todos os trabalhadores e toda e qualquer exposição a fluidos humanos.

A ocupação/profissão é uma variável previdenciária, trabalhista. O processo saúde-doença-trabalho se realiza no espaço de reprodução social. Nesse aspecto, o processo de trabalho é uma variável social de interesse para análises epidemiológicas e contribui para a construção de indicadores oportunos à compreensão da hepatite C no trabalho.

A hipótese de existência de rotas inexploradas de transmissão ocupacional do HCV - caso comprovada - implica a ampliação de direitos a protocolos de prevenção e reparação de danos a todos os trabalhadores expostos, contribuindo para a saúde, adequação de ambientes, processos e organização no trabalho; redução da magnitude da epidemia; redução de lacunas sobre as fontes de contaminação do HCV, agregando qualidade ao SVE-HV. Isso ajuda a iluminar o conhecimento científico sobre a infecção por HCV pela incorporação de novos condicionantes sociais e espectros de compreensão à sua trajetória histórico-geográfica.

\section{Considerações finais e desdobramentos}

Neste ensaio, iluminam-se possíveis rotas inexploradas de propagação do HCV. Entretanto, outras rotas "impensadas” podem ser descortinadas pelo diálogo com as pessoas sobre seus ambientes e processos de trabalho. Diálogo é troca e não mero preenchimento de formulários "bem” estruturados. Relatos de casos, plenos de subjetividades, podem contribuir para revelar "metades" desconhecidas pelos sistemas de informação, destacando-se que análises epidemiológicas fundamentadas em 50\% de certeza podem estar significativamente limitadas.

A potencial identificação de rotas ocupacionais de espalhamento do HCV implica colocar o controle desta infecção no trabalho como desafio à transformação de políticas de saúde do trabalhador. A magnitude (177,5 milhões de portadores no mundo), gravidade ( $80 \%$ de cronicidade), invisibilidade epidemiológica, limitações técnicas no desenvolvimento de imunizantes eficazes e seguros, alto custo (financeiro e efeitos adversos) terapêutico, inviabilidade prática e reduzida eficácia do uso de equipamentos de proteção individual na prevenção dessa infecção demandam pesquisas que incorporem o saber operário ${ }^{39}$.

Integração de saberes, no caso da hepatite $\mathrm{C}$ no trabalho, é decisão estratégica que possibilita adicionar segurança a processos de trabalho, saúde e qualidade de vida a trabalhadores e eficiência aos protocolos diagnósticos e terapêuticos.

\section{Contribuições de autoria}

Os autores contribuíram igualmente na concepção, projeto, levantamento, análise e interpretação dos dados; redação e revisão crítica do conteúdo intelectual do ensaio, bem como na aprovação final da versão publicada, responsabilizando-se integralmente pelo trabalho e pela integridade de qualquer parte deste ensaio.

\section{Referências}

1. Caldas JW. Vigilância em saúde do trabalhador: a formação de agentes multiplicadores no âmbito da Renast [dissertação]. Rio de Janeiro: ENSP/Fiocruz; 2018 [citado em 8 out 2020]. Disponível em: https://www.arca.fiocruz.br/bitstream/icict/26993/2/ ve_Jacqueline_Wilhelm_ENSP_2018.pdf

2. Antunes R, Alves G. As mutações no mundo do trabalho na era da mundialização do capital. Educ Soc. 2004 [citado em 8 out 2020];25(87):33551. Disponível em: https://www.scielo.br/pdf/es/ v25n87/21460.pdf

3. European Centre for Disease Prevention and Control. Hepatitis B and C surveillance in Europe 2012. Stockholm: ECDC; 2014 [citado em 15 set 2018]. Disponível em: https://www.ecdc.europa. eu/sites/default/files/media/en/publications/ Publications/hepatitis-b-c-surveillance-europe2012-july-2014.pdf
4. Petruzziello A, Marigliano S, Loquercio G, Cozzolino A, Cacciapuoti C. Global epidemiology of hepatitis $\mathrm{C}$ virus infection: an up-date of the distribution and circulation of hepatitis $\mathrm{C}$ virus genotypes. World J Gastroenterol. 2016;22(34):7824-40.

5. Centers for Disease Control and Prevention. Viral hepatitis: hepatitis $\mathrm{C}$ questions and answers for health professionals. Atlanta: CDC; 2018 [citado em 17 set 2018]. Disponível em: https://www.cdc. gov/hepatitis/hcv/hcvfaq.htm\#Ref06

6. World Health Organization. Guidelines for the care and treatment of persons diagnosed with chronic hepatitis C virus infection. Geneva: WHO; 2018 [citado em 18 set 2018]. Disponível em: http:// www.who.int/hepatitis/publications/hepatitisc-guidelines-2018/en 
7. Stanaway JD, Flaxman AD, Naghavi M, Fitzmaurice C, Vos T, Abubakar I, et al. The global burden of viral hepatitis from 1990 to 2013: findings from the Global Burden of Disease Study 2013. Lancet. 2016 [citado em 18 set 2018];388(10049):1081-8. Disponível em: http:// dx.doi.org/10.1016/S0140-6736(16)30579-7

8. Pratt B, Cheesman J, Breslin C, Do MT. Occupational injuries in Canadian youth: an analysis of 22 years of surveillance data collected from the Canadian Hospitals Injury Reporting and Prevention Program. Health Promot Chronic Dis Prev Can. 2016;36(5):89-98.

9. Health and Safety Executive. Health and safety at work: summary statistics for Great Britain 2016. [London]: HSE; 2016 [citado em 8 out 2020]. Disponível em: http://www.hse.gov.uk/statistics/ overall/hssh1516.pdf?pdf $=$ hssh1516

10. Brasil. Ministério da Saúde. Manual técnico do curso básico de vigilância em saúde do trabalhador no Sistema Único de Saúde. Brasília, DF: Ministério da Saúde; 2018 [citado em 15 out 2020]. Disponível em: http://renastonline.ensp. fiocruz.br/sites/default/files/arquivos/recursos/ manual_tecnico.pdf

11. Gaze R. Mulheres do lar, homens provedores e desigualdade na história social da hepatite C. In: Franco SP, Nascimento DR, Silveira AJT. Uma história brasileira das doenças. Vol. 7. Belo Horizonte: Fino Traço; 2017. p. 133-156.

12. Mol MPG, Greco DB, Cairncross S, Heller L. Hepatitis B and C in household and health services solid waste workers. Cad Saude Publica. 2015;31(Suppl 1):295-300.

13. Centers for Disease Control and Prevention. Viral hepatitis: surveillance for viral hepatitis: United States, 2016. Atlanta: CDC; [2018] [citado em 25 out 2018]. Disponível em: https://www.cdc.gov/ hepatitis/statistics/2016surveillance/index.htm

14. Brasil. Ministério da Saúde. Hepatites Virais 2018. Boletim Epidemiológico. 2018 [citado em 15 set 2018];49(31). Disponível em: http://www.aids. gov.br/pt-br/pub/2018/boletim-epidemiologico-dehepatites-virais-2018

15. Observatório Digital de Segurança e Saúde no Trabalho. [Brasília, DF]: SmartLab; 2017 [citado em 10 set 2018]. Disponível em: http://observatoriosst. mpt.mp.br

16. Instituto Brasileiro de Geografia e Estatística. Informalidade aumenta e continua a reduzir o desemprego. Agência IBGE de Notícias. 2017 Oct 31 [citado em 27 set 2018]. Disponível em: https://agenciadenoticias.ibge.gov.br/agencianoticias/2012-agencia-de-noticias/noticias/17508informalidade-aumenta-e-continua-a-reduzir-odesemprego.html.

17. Kamili S, Krawczynski K, McCaustland K, Li X, Alter M.J. Infectivity of hepatitis $C$ virus in plasma after drying and storing at room temperature. Infect Control Hosp Epidemiol. 2007;28(5):519-24.
18. Patel PR, Larson AK, Castel AD, GanovaRaeva LM, Myers RA, Roup BJ, et al. Hepatitis $C$ virus infections from a contaminated radiopharmaceutical used in myocardial perfusion studies. JAMA. 2006;296(16):2005-11.

19. European Centre for Disease Prevention and Control. Hepatitis B and C epidemiology in selected population groups in the EU/EEA. Stockholm: ECDC; 2018 [citado em 15 set 2018]. Disponível em: https://ecdc.europa.eu/sites/portal/ files/documents/Hepatitis-B-C-epidemiology-inselected-populations-in-the-EU.pdf

20. Bourlière M, Halfon P, Quentin Y, David P, Mengotti C, Portal I, et al. Covert transmission of hepatitis $\mathrm{C}$ virus during bloody fisticuffs. Gastroenterology. 2000;119(2):507-11.

21. Confederação Brasileira de Futebol. Regras de futebol 2015-2016. Rio de Janeiro: CBF; 2015 [citado em 25 out 2016]. Regra 5: o árbitro; p. 31-2. Disponível em: http://cdn.cbf.com.br/ content/201509/20150916113945_0.pdf

22. Maia ALS, Saito CA, Oliveira JAO, Bussacos MA, Maeno M, Lorenzi RL, et al. Acidentes de trabalho no Brasil em 2013: comparação entre dados selecionados da Pesquisa Nacional de Saúde do IBGE (PNS) e do Anuário Estatístico da Previdência Social (AEPS) do Ministério da Previdência Social. São Paulo: Fundacentro; 2015 [citado em 8 out 2020]. Disponível em: http://biblioteca.cofen.gov.br/wp-content/ uploads/2015/08/Acidentes-de-trabalho-noBrasil-em-2013.pdf

23. US Department of Labor. Occupational Safety and Health Administration. Regulations: standards: 29 CFR: Part 1910.1030. Washington, DC: [2006] [citado em 15 set 2018]. Disponível em: https://www.osha.gov/laws-regs/regulations/ standardnumber/1910/1910.1030

24. Novaes JR. Educação através das imagens. Rio de Janeiro: Pró-Reitoria de Extensão e Instituto de Economia da UFRJ; [2018] [citado em 24 out 2018]. Disponível em: https:/www.youtube.com/channel/ UCiUShB7aKjHRVipC2wrvZzg/vídeos

25. Galdino A, Santana VS, Ferrite S. Os centros de referência em saúde do trabalhador e a notificação de acidentes de trabalho no Brasil. Cad Saude Publica. 2012 [citado em 15 out 2020];28(1):14559. Disponível em: https://www.scielo.br/pdf/csp/ v28n1/15.pdf

26. Vasconcellos LCF. Vigilância em saúde do trabalhador: decálogo para uma tomada de posição. Rev Bras Saude Ocup. 2018 [citado em 15 set 2018];43(Suppl 1):e1s. Disponível em: https:// dx.doi.org/10.1590/2317-6369000029517

27. Dia do Trabalhador: evento na Fiocruz aborda acidentes de trabalho no Brasil (3/5). Agência Fiocruz de Notícias. 2018 Apr 27 [citado em 10 set 2018]. Disponível em: https://agencia.fiocruz. br/dia-do-trabalhador-evento-na-fiocruz-abordaacidentes-de-trabalho-no-brasil-35 
28. Ramazzini B. As doenças dos trabalhadores. 4th ed. Estrêla R, tradutor. São Paulo: Fundacentro; 2016 [citado em 8 out 2020]. Disponível em: https://48209fd4-9e54-4385-b712-c09bfc7c2b87. filesusr.com/ugd/15557d_34bf07d01e944518a21e8 3c270f1cea4.pdf

29. Fórum Intersindical Saúde-Trabalho-Direito. Fórum Intersindical de Formação em SaúdeTrabalho-Direito para a Ação em Saúde do Trabalhador. Boletim Intersindical. 2015 [citado em 10 set 2018];1(0):2-3. Disponível em: https:// docs.wixstatic.com/ugd/15557d_6193c64e46ea4d9 193836671d517b95e.pdf

30. Vasconcellos LCF, Aguiar L. Saúde do trabalhador: necessidades desconsideradas pela gestão do Sistema Único de Saúde. Saúde Debate. 2017 [citado em 15 out 2020];41(113):605-17. Disponível em: https:/www.scielo.br/pdf/sdeb/v41n113/01031104-sdeb-41-113-0605.pdf

31. Allison RD, Conry-Cantilena C, Koziol D, Schechterly C, Ness P, Gibble J, et al. A 25-year study of the clinical and histologic outcomes of hepatitis c virus infection and its modes of transmission in a cohort of initially asymptomatic blood donors. J InfectDis. 2012;206(5):654-61.

32. Slot E, Janssen MP, Marijt-van der Kreek T, Zaaijer HL, van de Laar TJ. Two decades of risk factors and transfusion-transmissible infections in Dutch blood donors. Transfusion. 2016;56(1):203-14.

33. Karmochkine M, Carrat F, Dos Santos O, Cacoub P, Raguin G. A case-control study of risk factors for hepatitis $\mathrm{C}$ infection in patients with unexplained routes of infection. J Viral Hepat. 2006;13(11):775-82.

34. Markov PV, van de Laar TJ, Xiomara V, Aronson SJ, Weegink CJ, van den Berk GE, et al. Colonial history and contemporary transmission shape the genetic diversity of hepatitis $C$ virus genotype 2 in Amsterdam. J Virol. 2012;86(14):7677-87.

35. Leão LHC, Vasconcellos LCF. Cadeias produtivas e a vigilância em saúde, trabalho e ambiente. Saude Soc. 2015 [citado 15 out 2020];24(4):1232-43. Disponível em: https:/www.scielo.br/pdf/sausoc/ v24n4/1984-0470-sausoc-24-04-01232.pdf

36. Lauring AS, Andino R. Quasispecies theory and the behavior of RNA viruses. PLoS Pathog. 2010 [citado em 10 set 2018];6(7):e1001005. Disponível em: https://doi.org/10.1371/journal.ppat.1001005

37. Chapman LE, Sullivent EE, Grohskopf LA, Beltrami EM, Perz JF, Kretsinger K, et al. Recommendations for postexposure interventions to prevent infection with hepatitis B virus, hepatitis $\mathrm{C}$ virus, or human immunodeficiency virus, and tetanus in persons wounded during bombings and other masscasualty events: United States, 2008. MMWR Recomm Rep. 2008;57(RR-6):1-19.

38. International Labour Organization. List of occupational diseases (revised 2010): identification and recognition of occupational diseases: criteria for incorporating diseases in the ILO list of occupational diseases. Geneva: ILO; 2010 [citado em 2 jan 2016]. (Occupational Safety and Health Series, No. 74). Disponível em: http:// www.ilo.org/wcmsp5/groups/public/---ed_protect/--protrav/---safework/documents/publication/ wcms_150323.pdf.

39. Vasconcellos LCF, Almeida CVB, Guedes DT. Vigilância em Saúde do trabalhador: passos para uma pedagogia. Trab Educ Saude. 2009 [citado em 15 out 2020];7(3):445-62. Disponível em: https:// www.scielo.br/pdf/tes/v7n3/04.pdf 